\title{
ON THE DISTRIBUTION
}

OF THE

\section{“TUBERCLE BACILLI" IN THE LESIONS OF PHTHISIS.}

\author{
BY \\ PERCY KIDD, M.A., M.D.Oxon., \\ ASSISTANT PHYSICIAN TO THE HOSPITAT FOR CONSUMPTION AND DIEEASES \\ OF THE CHEST, BROMPTON.
}

Received April 13th-Read December 9th, 1884.

THE publication of Koch's memorable paper in the 'Berliner klinische Wochenschrift,' in 1882, has led to a large number of inquiries into the relation of the so-called tubercle bacilli to the process of tuberculosis. It may be safely said that all attempts to discredit the existence of these bacilli, or to assign to them inorganic properties, have entirely failed. Indeed, it would seem rather that there is a disposition to accept this particular microorganism as a full and sufficient explanation of the whole question of tuberculosis.

Tubercle bacilli, $i$. e. bacilli having the special re-action to certain aniline dyes discovered by Koch, are now known to be present in the pulmonary cavities of all cases of true "tubercular phthisis."

It would also be granted that the same organisms can be detected in the sputum of nearly all cases of this 
disease, at some stage or other of the patient's life. They have been found in the lesions of artificial tuberculosis of animals and in acute miliary tuberculosis and phthisis in the human subject. It seems that whereas the bacilli are very numerous in artificial tuberculosis, they are less abundant in what are termed "tuberculous" diseases in man. Under the last heading it is usual now to include not only acute miliary tuberculosis and phthisis, but also scrofulous glandular and joint affections, and even lupus.

The experimental side of the question has been ably investigated in this country by Mr. Watson Cheyne, on the lines laid down by Koch himself.

Mr. Cheyne's report published in the 'Practitioner' of April, 1883, strongly confirms Koch's conclusions. The results of the same observer's examination of a certain number of cases of acute miliary tuberculosis and phthisis agree with Koch's experience. Hitherto, however, the number of observations on the distribution of "tubercle bacilli" in the tissues of man has not been large in England.

It seemed desirable, therefore, in view of the great importance of the subject, to inquire into the distribution of these bacilli in a large number of cases of phthisis.

It may be stated at once that this paper will be confined mainly to the consideration of the anatomical relations of these micro-organisms to the various lesions found in this disease.

No attempt will be made to discuss the etiology of phthisis or tuberculosis, except in so far as any information concerning the local distribution of the "tubercle bacilli" may seem to have a distinct bearing on the question.

The results of the present investigation refer mainly to the lung and in a less degree to the larynx, intestine, and lymphatic glands. Other organs and tissues have been examined in comparatively isolated cases and the results obtained will be given for what they are worth. 
In the case of the lung, the object kept in view was to determine the anatomical distribution of the bacilli in the various lesions comprised in the phthisical process ; in other words, to find out whether they were present in all the lesions of this disease, and if not, to determine their seat of election.

In describing the anatomical lesions it will be convenient to avoid the use of the term "tubercle" as far as possible, especially in the case of the lung, so as to aroid misconception.

The following list may be said to comprise the main pulmonary lesions of phthisis :

(1) Nodules in size from a millet-seed upwards.

(2) Tracts of consolidation, mostly lobular.

(3) Fibroid induration.

(4) Cavities.

The "nodules" may occur singly or in groups, may be transparent, opaque, or actually softening.

The "tracts of consolidation" may present all stages from commencing catarrhal pneumonia (pinkish consolidation) to complete caseation (caseous pneumonia). Fibrinous matter and small cells are found in some cases in groups of alveoli.

The nodular lesions include bronchioles, alveolar passages and their corresponding alveoli, together with the alveolar walls. Such lesions may be regarded as broncho-pneumonic.

In the case of phthisis and in most instances of acute miliary tuberculosis, this description applies not only to the larger nodules, but also to the true miliary granulation.

The histological characters of these several lesions are too well known to justify a detailed account of them here. It must be borne in mind, however, that in the case of phthisis the very earliest miliary nodules are nearly always associated with a certain amount of fibroid growth. This is found also in the corresponding lesions of acute miliary tuberculosis in some cases, but in a very much 
slighter degree. This distinction must not be lost sight of.

The consolidation which has been incidentally described as lobular is sometimes apparently "lobar," and has been so termed by some writers. This, however, is probably seldom the case. A careful examination rarely fails to establish the lobular origin and nature of such consolidation.

The term "cavities" is intended to include true pulmonary and so-called bronchiectatic cavities.

Pigmentation may be associated with any of the foregoing changes.

\section{Methods employed.}

Hardening was effected by means of alcohol only, except in a few cases, where a mixture of alcohol and chromic acid one sixth per cent. was used.

The sections were stained with the Weigert-Ehrlich solution of fuchsin, then treated with nitric acid, and subsequently stained with methylene blue.

Oil of cloves was used for clearing the sections at first. But since Koch's recommendation of oil of cedar in his complete memoir ("Die Aetiologie der Tuberkulose," 'Mittheil. aus d. Kais. Gesundheitsamte,' Bd. ii), I have invariably used this instead, as the aniline colours are insoluble in it. I have also discarded the ordinary chloroform solution of Canada balsam, and have used instead a solution of balsam in benzol for mounting sec. tions.

In all cases the sections were examined with Abbé's condenser in conjunction with Zeiss's microscope, oculars ii and iv. The lenses used were Zeiss's F, Hartnack's Nos. 4 and 7.

Koch seems to suggest that the use of chromic acid as a hardening agent interferes with the staining of the bacilli. My experience in the six or seven cases that I used chromic acid was that the bacilli were quite as well 
stained as when I used absolute alcohol only. I gave up chromic acid, however, for the reason that it interferes with the staining of the tissues with methylene blue. In chromic acid specimens the tissues acquire a faint greenish stain with the blue solution.

The blue staining also is far more perfect when the sections are cleared with oil of cedar instead of oil of cloves.

\section{Cases.}

1. Eliza Q.-Chronic phthisis.-(a.) Emphysematous lung studded with nodules of the size of a hemp-seed or rather larger. The nodules consist of aggregations of caseating areas representing groups of alveoli, alveolar passages, and bronchioles. The central parts of the nodules are caseous, the peripheral portions consist of a fibro-cellular zone divisible into an internal and external territory ; the latter containing more closely crowded cells of smaller size. Numerous pigmented giant-cells are scattered through the fibrocellular zone. Connective-tissue development is proceeding in this zone. Some of the nodules contain thickened and dilated bronchioles; in some cases the thickening is mainly of a fibrous nature, in others it consists of a cellular infiltration. Scattered small groups of bacilli are seen in comparatively few nodules, and are situated in caseating alveoli. No bacilli in giant-cells. Some micrococci in caseous matter in a few spots.

(b.) Scrapings from the wall of a large cavity contained numerous bacilli.

(c.) Scrapings from a partially softened caseous mass contained few bacilli.

(d.) Scrapings from a firm caseous part showed no bacilli.

I have described the rough anatomy of the nodules in the present case as being a fairly typical specimen of the ordinary discrete nodular form of the disease. In the remaining cases it may be assumed that the nodules conform in the main to the above type, unless a statement is made to the contrary.

2. Edwin B.-Phthisis.-(a.) Lung with commencing catarrhal 
pneumonia, through which are scattered a few small fibro-caseous nodules. No bacilli in any part.

(b.) Emphysematous lung studded with similar nodules. No bacilli found.

3. John P.-Phthisis.-(a.) Emphysematous lung studded with racemose groups of fibro-caseous miliary nodules. No bacilli found in any part.

(b.) Thickened pleura containing fibro-caseous miliary tubercles, with giant-cells. No bacilli found.

4. Gustav G.-Acute phthisis.-(a.) Fibro-caseous nodules distributed through emphysematous lung. Bacilli in small groups in a few caseous spots, large numbers in the walls of microscopical cavities and in infiltrated brochioles.

(b.) Fibro-caseous miliary nodules in thickened pleura. No bacilli found.

5. James W.-Phthisis. - (a.) Fibro-caseous nodules in slightly emphysematous lung. No bacilli found.

(b.) Pleura much thickened, and containing fibro-caseous miliary tubercles. No bacilli found.

6. Wm. F.-Phthisis.-Spongy lung studded with small whitish nodules consisting mainly of fibrinous matter blocking up the alveoli, and containing scanty small cells. Some alveoli filled with blood. No bacilli found.

7. Ellen B.-Phthisis.-Fibro-caseous racemose nodules in spongy lung. Bacilli scanty, and only found in caseous alveoli here and there.

8. Jane S.-Phthisis. - (a.) Opaque miliary nodules in cdematous lung, consisting mainly of alveoli filled with fibrinous matter and containing here and there a few large cells with indistinct outline. Bacilli extremely few and scattered in the cellular parts only.

(b.) Larynx. Great thickening of aryteno-epiglottic folds, without ulceration. Miliary tubercles in different stages and large-celled infiltration in submucous tissue. Bacilli few and scattered in epithelioid patches.

9. Henry J.-Chronic phthisis, extensive emphysema, much pigmentation of lung and pleura.-(a.) Pleura. Fibro-caseous miliary tubercles. No bacilli found.

(b.) Lung containing similar but larger nodules, in which caseation is less advanced, and traces of cells are visible. Bacilli in some nodules, but as a rule scanty; large numbers in a few spots.

10. John W.-Phthisis; disseminated miliary tuberculosis.-(a.) Lung containing miliary caseating nodules, with numerous giantcells in coarsely reticulated zone. No bacilli found in giant-cells, 
or in any part of most of the nodules. In a very few cases, two or three bacilli were found in caseating alveoli.

(b.) Liver containing numerous fibro-caseous miliary tubercles, with numerous giant-cells. No bacilli found, but, in a few sections some granules of the size of micrococci were found stained red. These granules were not in the tubercles, but were contained in livercells in the neighbourhood of tubercles.

(c.) Miliary tubercle of pia mater, with scarcely any caseation, in connection with the wall of a small vessel. Bacilli present in considerable numbers among epithelioid cells.

11. Louisa F.-Phthisis-Emphysematous lung containing fibrocaseous miliary nodules. Bacilli in small numbers in a few caseous spots, and in larger numbers in microscopical cavities contained in the nodules. A few bacilli in infiltrated bronchioles in some cases.

12. Eliza H.-Phthisis.-Lung examined fresh after freezing.-(a.) Small fibro-caseous nodules. Bacilli rather few in caseous alveoli, and in surrounding large-celled areas.

(b.) Firm, caseous, pneumonic tract. Caseation uniform. No bacilli found.

13. Amelia B.-Phthisis; pulmonary and laryngeal.-(a.) Tuberculous lymphangitis of lung. A string of miliary nodules attached to either side of the thickened interlobar septum, lung tissue around spongy. Microscopically, the interlobar septum contained caseous tracts with giant-cells, the nodules on either side of it exactly resembling those found in the lung in ordinary cases of phthisis, and consisting of groups of caseating alveoli. Microscopical cavities in nodules here and there. The miliary nodules were evidently secondary to the caseation of the interlobar septum. Bacilli in moderate numbers in some of the nodules where caseation is recent, and in the walls of two microscopical cavities. No bacilli in the old caseous matter of septum, or in the giant-cells of this part.

(b.) Larynx. Deep tuberculous ulceration of the inter-arytenoid fold. Scanty fibro-caseous miliary tubercles, and abundant largecelled infiltration. Bacilli in moderate numbers on the ulcerated surface, and in the more superficial tubercles and infiltration. Bacilli seen in one giant-cell.

14. Alfred F.-Phthisis.-Emphysematous lung containing small nodules, in which the fibroid tendency is unusually pronounced. No bacilli found.

15. Henry B.-Phthisis.-(a.) Tracts of catarrhal pneumonia, with scanty caseating foci. No bacilli found.

(b.) Small fibro-caseous nodules in spongy lung. No bacilli found.

16. Eleanor M.-Phthisis.-Tuberculous lymphangitis. Thickened 
pleura, containing miliary tubercles and caseous tracts. Subjacent lung almost entirely spongy, with exception of its extreme sub. pleural layer, in which there are numerous fibro-caseous miliary nodules continuous with the thickened pleura. These nodules resemble those commonly found in the lung, consisting of infiltrated alveoli and alveolar walls with microscopical cavities in the caseating parts here and there. Bacilli in considerable numbers in the minute cavities. None elsewhere. (See Plate II, fig. 3.)

17. George F.-Large casenus mediastinal glands, with subjacent miliary tuberculosis of lung.

(a.) Caseous matter from gland, consisting simply of fine detritus, contained no bacilli.

(b.) Fibro-caseous miliary nodules in lung. In most cases contained no bacilli; but in a few cases one or two bacilli were seen in alveoli whose cells were beginning to caseate.

18. Eleanor C.-Phthisis. - Fibro-caseous miliary nodules in emphysematous lung. Much pigmentation. Bacilli very scanty, in a few caseous spots.

19. Richard H.-Phthisis ; pneumothorax.-Examined fresh. Lung containing fibro-caseous nodules of various sizes, with much smallcelled infiltration of alveolar walls. Bacilli very scanty, and only found in extremely few nodules in caseating alveoli. Micrococci in places in large numbers.

20. John P.-Phthisis; emphysema.-(a.) Emphysematous lung studded with fibro-caseous miliary nodules. Two different parts examined. (i) Early stage: nodules very scanty. (ii) Later stage : nodules more numerous, and alveolar walls pigmented and infiltrated with small cells. In a very few sections out of a large number bacilli were found in the earlier lesions in caseous spots. None in (ii) later stage.

(b.) Firm, caseous suprarenal capsules. Closely crowded caseating areas, with giant-cells and irregular large-celled infiltration. A few bacilli were found in some few caseous spots and in surrounding large-celled zone.

21. Jeremiah H.-Phthisis; pneumothorax.-(a.) Small fibro-caseous nodules in emphysematous lung. Bacilli in moderate numbers in microscopical cavities in the nodules; less abundant in walls of infiltrated bronchioles. Scattered groups in caseous aveoli, enormous numbers in a few spots close to minute cavities.

(b.) Bronchial gland containing caseous areas and miliary tubercles, with giant-cells in their peripheral course of reticulated zone. A few bacilli in scattered caseous spots and in tubercles here and there; rarely more than two bacilli in the same field. 
(c.) Tubercular ulceration of small intestine. No bacilli found in most sections. One or two bacilli in a few fibro-caseous tubercles in submucosa.

22. Susan H.-Phthisis.-Tuberculous lymphangitis of lung, starting from thickened caseous interlobar septum. (Lesions exactly like those in Case 13.) No bacilli found in nodules or in caseous pleura

23. Thomas C.-Phthisis.-(a.) Spongy lung, with scattered small fibro-caseous nodules. Bacilli scanty, and only in scattered caseous spots in nodules.

(b.) Spleen. Amyloid degeneration and irregular caseous patches containing giant-cells. No bacilli found.

(c.) Mediastinal glands. Fibro-caseous miliary tubercles, with numerous giant-cells. No bacilli found.

24. John G.二Phthisis.-Spongy lung, containing closely set miliary fibro-caseous nodules. Bacilli very numerous in the nodules, among the caseating epithelioid cells, in caseous tracts, in the infiltrated walls of bronchioles, and in small microscopical cavities.

25. Richmond W. - Acute phthisis. - (a.) Caseous pneumonia. Caseation almost uniform and very firm. Contents of alveoli fibrinous in many parts. Scarcely a trace of cellular structure in most parts. No bacilli could be found after careful examination of different parts.

(b.) Tubercular ulceration of small intestine. Miliary tubercles and large-celled infiltration in submucosa; tubercles mostly recent. Bacilli very numerous, and widely distributed in tubercles and epithelioid cells; more abundant in tubercles. Bacilli in a few giant. cells.

26. Case of phthisis, sent by Dr. Powell.-Extensive catarrhal pneumonia, with irregular caseating patches. Bacilli few, and only in scattered points where caseation is incomplete. No bacilli where caseation is advanced.

27. Emma W.-Phthisis.-Early caseous pneumonia of very irregular character. In some parts catarrhal pneumonia; elsewhere caseous patches, in which are scattered softening foci. Bacilli very irregularly distributed. The walls of microscopical cavities contain enormous numbers. In most sections two or three large groups are seen in caseous alveoli and interalveolar spaces, none in catarrhal pneumonic parts. The bacilli are not widely disseminated, but seem to be exclusively collected in large groups. Walls of small veins in places infiltrated with epithelioid cells, among which bacilli were seen in a few instances.

28. Stephen H.-Phthisis; pneumothurax.-(a.) Caseous pneu. monia like that in last case. Much catarrhal pneumonia. Bacilli 
in small numbers, but widely diffused through parts where caseation is early.

(b.) Mediastinal gland containing miliary tubercles and epithelioid areas. Caseation commencing at various points. Bacilli numerous both in tubercles and in large-celled infiltration, especially in cortical portion of gland where the disease is most marked.

29. Emily P.-Phthisis. - (a.) Caseous pneumonia; caseation irregular; much catarrhal pneumonia. Bacilli scattered in small numbers where caseation is less advanced, collected in groups in a few instances in caseous parts.

(b.) Caseous pus from Fallopian tubes, consisting simply of fine detritus without any cell structure. No bacilli.

30. Edith G.-Phthisis.-Irregular caseous pneamonia resembling last case. Bacilli in enormous numbers, collected in groups in caseous parts. None in catarrhal pneumonic patches.

31. Emily G.-Phthisis.-(a.) Caseous pneumonia. Caseation firm and uniform. Contents of alveoli fibrinous in some parts. Cellular elements in most sections absent or very scanty. No bacilli could be found although numerous sections were taken from different parts.

(b.) Larynx. Epiglottis enormously thickened and only very slightly ulcerated. Numerous miliary tubercles in various stages in submucosa, with abundant giant-cells; also extensive large-celled infiltration. Bacilli very few in tubercles and in the base of the ulcers.

32. Kate G.-Phthisis.-Caseous pneumonia. Caseation very firm, but less uniform than in last case, with scattered patches of catarrhal pneumonia. No bacilli found in caseous parts. One group, however, found at margin of caseation in an alveolus containing an increased number of epithelial cells.

33. Fred. H.-Lympho-sarcoma of Mediastinal Glands invading the lung, which contained also crops of miliary nodules, irregularly pigmented patches of greyish consolidation resembling caseous pneu. monia, and some small cavities.-(a.) Mediastinal glands showed the usual lympho-sarcomatous structure, and contained no bacilli.

(b.) Pericardium thickened, and containing caseating tracts. Bacilli in a few large groups among caseous material.

(c.) Lung. 1. The contents of small cavities contained extremely few bacilli.

2. Large lymphomatous nodules showed same structure as medi. astinal glands, and were free from anything like caseation. No bacilli.

3. Greyish consolidated parts showed the structure of caseous 
pnenmonia combined with much catarrhal pneumonia. Bacilli in great numbers in various parts when caseation is early among epithelioid cells, and in microscopical carities. A few also in infiltrated walls of bronchioles.

4. Miliary nodules consist of groups of caseating alveoli and bronchioles exactly like miliary tubercles. No bacilli found in these nodules.

34. George B.-Acute miliary tuberculosis.-(a.) Lung with varying amount of catarrhal pneumonia stuffed with enormous numbers of slightly opaque miliary and submiliary nodules, and scattered fibro-caseous nodules of larger size. In nearly all cases the nodules obviously consisted of groups of alveoli filled with a finely granular material, in which were traces of cells in some instances. Here and there an alveolus was filled with large epithelial cells. Frequently an infiltrated caseating bronchiole was seen in the midst of the nodule or at one side of it. A large-celled infiltration of the walls of small veins was seen in some sections. Groups of bacilli were found in a few of the larger caseous nodules, but none were detected in the smaller ones except in the caseating walls of some of the bronchioles. Numerous sections from different parts of the lung gave the same result.

(b.) Spleen. Numerous fibro-caseous miliary tubercles with giantcells. No bacilli found.

(c.) Kidney. Cortex contained scanty caseating miliary nodules and irregular patches of small-celled growth in which were traces of tubules and glomeruli. Bacilli few, and only in caseous spots.

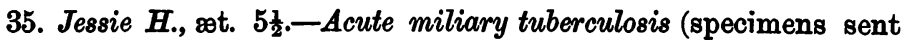
by Dr. Angel Money).-(a.) Lung with irregular catarrhal pneumonic tracts, studded with rather scanty caseating nodules of the size of hemp-seed. The nodules consist of groups of alveoli filled with caseating epithelioid cells, infiltrated bronchioles, and an irregular peripheral small-celled zone; giant-cells scanty. Centres of nodules completely caseous in places. Bacilli present in enormous numbers in almost every single nodule, especially among epithelioid cells, also in giant-cells, bronchioles, and in smaller numbers in older caseous spots. No bacilli in small-celled zone, or in surrounding catarrhal pneumonic parts. In one place the walls of a minute artery were seen to be infiltrated with epithelioid cells, which gave rise to a nodular projection from the intima into the lumen of the vessel, which was patent and filled with blood-corpuscles. Bacilli were present in great numbers among the epithelioid cells in the vascular wall. (See Plate I, figs. 1 and 2.)

vOL. LXVIII. 
(b.) Liver. Scanty miliary tubercles. Bacilli in rather small numbers in giant-cells, and among the epithelioid cells.

(c.) Spleen. Numerous miliary tubercles. Bacilli in large numbers among epithelioid cells and in giant-cells.

36. Hubert F. L., æt. 3.-Acute miliary tuberculosis (specimens sent by Dr. Angel Money).-(a.) Lung. Irregular patches of catarrhal pneumonia and small caseous nodules and tracts. Bacilli in large numbers in caseating traets, comparatively few in nodules, none in catarrhal pneumonic parts.

(b.) Kidney. Scanty miliary tubercles, in which there are traces of caseation, and islets of small-celled infiltration in cortex. No bacilli found.

(c.) Liver. Miliary tubercles. Bacilli very few in giant.cells, among epithelioid cells, and in caseating foci.

37. Case of acute miliary tuberculosis in a child (specimens sent by $\mathrm{Dr}$. Chaffey).-(a.) Iung containing scattered nodules as large as hemp-seed. Nodules mainly consist of alveoli filled with fibrinouslooking material, very few large cells, and scanty giant-cells. Bacilli in great numbers in alveoli, few in giant-cells.

(b.) Liver. Extreme fatty degeneration and scanty miliary tubercles, some recent, most of them fibro-caseous. Bacilli few in giant-cells, among epithelioid cells, and, in a few cases, in more recent caseous foci.

38. Case of acute miliary tuberculosis in a child (another case sent by Dr. Chaffey). - Lung thickly studded with miliary nodules, most of which are undergoing a fibro-caseous change. Bacilli few and scattered, among epithelioid cells, in some giant-cells, and in caseating spots.

39. George H.-Acute miliary tuberculosis.-(a.) Lung œdematous and studded with miliary caseating nodules. Bacilli in small numbers and scattered in early caseous spots, where traces of epithelioid cells are to be seen. None in surrounding tracts of catarrhal pneumonia.

(b.) Kidney. Scattered submiliary tubercles. Bacilli in rather small numbers in most of the tubercles, among epithelioid cells, and in caseating foci, groups in some cases, Some Malpighian capsules contain a finely granular crescentic zone partially surrounding the degenerate glomerulus, the whole capsule being encircled by an outer epithelioid zone. Bacilli in varying numbers in the crescentic internal amorphous (caseating) zone, and in the peripheral epithelioid ring.

(c.) Liver. Numerous submiliary tubercles. Bacilli few and scattered among epithelioid cells, none in giant-cells, which are scanty. 
(d.) Spleen. Submiliary tubercles. Bacilli very few and scattered among epithelioid cells and in a few giant-cells.

40. Amos P.-Acute miliary tuberculosis. - Lung containing evenly distributed miliary tubercles, in which caseation is beginning in nearly all cases. Bacilli few in giant-cells and among epithelioid cells.

41. Geo. C.-Phthisis.-Thick fibroid wall and trabecula of large cavity. Bacilli in moderate numbers in superficial caseous layer in both positions. None in deeper parts.

42. Eli M.-Phthisis.-(a.) Fibroid wall of small suppurating cavity. No bacilli found in sections, in consequence probably of superficial layer having been detached in preparation, for a scraping from hardened cavity wall showed abundant bacilli.

(b.) Tubercular ulceration of small intestine in early stage. No bacilli found in most sections. One or two bacilli in a few fibro. caseous tubercles.

(c.) Mediastinal gland containing firm caseating patches with giant-cells. No bacilli found.

43. James M.-Phthisis. - Thick fibroid wall of small cavity. No bacilli seen in cavity wall in sections. A scraping from the cavity wall after hardening showed a few bacilli.

44. Hugh C.-Phthisis.-(a). Pleura thickened, and containing fibro-caseous miliary tubercles with numerous giant-cells and caseating tracts. No bacilli found.

(b.) Trachea. Superficial ulceration with necrotic caseating surface. Small-celled infiltration of mucosa and round about mucous glands and ducts. No miliary tubercles or large-celled growth. No bacilli in the tissues; one or two are seen on the ulcerated surface.

45. Edward S.-Phthisis. - Pleura thickened and containing caseous tracts. No bacilli found.

46. James $L$.-Sacculated bronchiectasis; abscess of brain.-Exten. sive excavation of one lung, with foul, inspissated, secretion-like softening caseous matter. Bronchi generally dilated. No "tuber. culous" lesion.

(a.) Fotid purulent expectoration during life contained no bacilli, but numerous micrococci.

(b.) Discharge from cavity after tapping during life contained micrococci, but no bacilli.

(c.) Contents of cavities after death contained micrococci, but no bacilli.

(d.) Pus from cerebral abscess contained micrococci, but no bacilli. 
47. Charles H.-Sacculated bronchiectasis; abscess of brain.-Cavities in right upper lobe with contents like those in last case. Bronchi generally dilated. No " tuberculous" lesion.

(a.) Cavity contained micrococci, but no bacilli.

(b.) Pus from cerebral abscess gave a similar result.

48. Charles L.-Aneurysm of aorta, compressing left bronchus.Excavation of left lung (bronchiectatic). Cavity contents contained some micrococci and a few putrefactive bacilli, but no "tubercle bacilli."

49. Margaret S.-Syphilitic stricture of bronchus.-Excavation of corresponding lung (bronchiectatic). Cavity secretions contained no " tubercle bacilli." A few micrococci.

50. Archibald M.-Malignant disease of lung; sarcoma.-Nodules of all sizes and small cavities containing blood-stained grumous fluid.

(a.) Cavity secretions contained no " tubercle bacilli."

(b.) Nodular growths in lung contained no bacilli.

51. Walter A. - Laryngeal phthisis.-Tubercular ulceration and great thickening of aryepiglottic fold. Tubercles scanty. Extensive large-celled infiltration. Bacilli scattered in small numbers on the floor of the ulceration and in the submucous tubercles and epithelioid patches.

52. Charles L.-Laryngeal phthisis.-Tuberculous ulceration of larynx and trachea. Small tumours apparently situated on vocal cords, but really springing from lateral aspect of interarytenoid fold. Bacilli in large numbers in the tubercles and epithelioid areas, in arynx and trachea, and even more abundant in the small tumours, which consist of collections of miliary tubercles with inter. vening epithelioid areas.

53. John R.-Phthisis.-Larynx. Tubercular ulceration of inter. arytenoid fold. Numerous caseating miliary tubercles, and largecelled growth in mucosa and submucosa. Bacilli present in very scattered spots and in small numbers at the surface, and in the more superficial tubercles and epithelioid areas.

54. Wm.J. T.-Phthisis. -(a.) Larynx. Deep tubercular ulceration of the interarytenoid fold, exposing the muscular layer. Bacilli in enormous numbers on the floor of the ulceration and in the sub. jacent tubercles and epithelioid areas.

(b.) Intestine. Deep tubercular ulceration of ileum. Bacilli numerous at ulcerated surface and in submucous tubercles. Some bacilli in places in subserous tubercles.

55. Wm.F.-Phthisis, pulmonary and laryngeal.-Larynx. Miliary nodules, without ulceration in their immediate vicinity, in the 
"sinus pyriformis," consisting mainly of small-celled growth, with scattered, faintly staining, large-celled areas. A very few bacilli were found in the latter position in a few sections only.

56. George G.-Phthisis, pulmonary and laryngeal.-Larynx. Tubercular ulceration, with great fibroid thickening, both in the base of the ulcers and in their neighbourhood. Bacilli extremely scanty in tubercles here and there.

57. Thomas C.-Phthisis, pulmonary and laryngeal. - Larynx. Great swelling of epiglottis, with scarcely any ulceration. Miliary tubercles and large-celled infiltration. Bacilli widely diffused in large numbers in tubercles and large-celled patches. Many giantcells contain bacilli.

58. John P. J.-Laryngeal phthisis.-(a.) Tuberculous ulceration of larynx and trachea. Tubercles recent in larynx ; fibro-caseous in trachea; epithelioid areas. Bacilli scattered in very small numbers through tubercles, and large-celled infiltration in larynx and trachea.

(b.) Tuberculous ulceration of cæcum. Bacilli few and scattered in caseating tubercles and in tubercles of reticulated type.

(c.) Mesenteric gland, containing recent miliary tubercles and larger fibro-caseous nodules. Bacilli scattered in small numbers through both varieties of nodule.

59. Frederick J.-Laryngeal phthisis.-(a.) Pharynx. Tubercular ulceration. 1. Small superficial ulcers with subjacent miliary tubercles and epithelioid areas. Bacilli scattered in small numbers in tubercles and large-celled patches.

2. Large sharply-cut ulcers with much fibroid growth in their bases. Scanty miliary tubercles of fibro-caseous structure. No bacilli found.

(b.) Tubercular ulceration of larynx. A small tumour growing from interarytenoid fold amidst the ulceration, and consisting of miliary tubercles and epithelioid areas. Bacilli numerous in both lesions of tumour.

60. Elizabeth S.-Phthisis. - Tuberculous ulceration of small in. testine. Bacilli very few, and found in a comparatively small number of sections in the floor of the ulceration and in fibro-caseous submucous tubercles. In a few instances groups of small spherical granules like micrococci stained red were found in the submucosa. These bodies appeared to be situated in fat-cells. In the same sections other fat-cells contained groups of somewhat similar granules stained blue.

61. William H.-Phthisis.-Tubercular vlceration of small intestine with numerous fibro-caseous miliary tubercles in the subserous tissue. Great atrophy of intestine. No bacilli found except in one 
section, where a caseating submucous tubercle contained one wellmarked bacillus.

62. Janet W.-Phthisis.-Intestine. Superficial ulceration and cellular infiltration of mucous coat. No tubercles or " tuberculous" structure. Lymphatics stuffed with small cells. Fibroid induration where the disease is most advanced. Great atrophy of intestine. No bacilli found.

63. Henry B.-Phthisis.-Intestine. Tubercular ulceration in different stages in different parts. No bacilli found in early or advanced ulceration.

64. Emily C.-Phthisis.-Intestine. Deep tubercular ulceration exposing muscular layer. Submucous tubercles. Bacilli fairly numerous at the ulcerated surface and in caseating tubercles.

65. John M.-Phthisis.-Superficial ulceration of small intestine, with abundant small-celled infiltration of mucosa and submucosa. Fibroid thickening of base of ulcers in places. No tubercles or epithelioid areas. No bacilli.

66. James B.-Phthisis. - (a.) Superficial ulceration of small intestine, with small-celled infiltration of mucosa and submucosa. No tubercles or epithelioid areas. No bacilli found.

(b.) Similar infiltration, but no ulceration. No bacilli found.

Great atrophy of intestine in both cases.

67. John H.-Abscess of liver.- Ulceration of large intestine with enormous fibroid thickening of gut, probably due to old dysentery. Small-celled infiltration of the whole intestinal wall, with widely disseminated micrococci, but no bacilli.

68. John H.-Phthisis.-Bronchial gland containing caseating areas and fibro-caseous miliary tubercles, with giant-cells. No bacilli found.

69. Annie E.-Phthisis.-Bronchial gland. Similar disease to that in last case. No bacilli found.

70. Daniel E.-Phthisis.-(a.) Mesenteric gland. Caseation com. mencing in most parts, numerous miliary tubercles and epithelioid tracts. Bacilli in enormous numbers in all lesions in every single section examined (see Plate II, fig. 4).

(b.) Liver. Fatty degeneration, early cirrhosis and miliary tuber. culosis. Bacilli in fair numbers in giant-cells and among epithelioid cells of tubercles.

71. Samuel L.-Phthisis.-Mesenteric gland in state of uniform firm caseation. No bacilli found.

72. Henry P.-Phthisis.-Mediastinal gland containing caseating areas and fibro-caseous miliary tubercles. Bacilli extremely scanty in tubercles. 
73. Arthur T.-Phthisis.-Tracheal gland. Caseating areas and miliary tubercles, some recent, others fibro-caseous. Bacilli in very small numbers in few sections in tubercles and caseous patches.

74. George B.-Aneurysm of Aorta.-Recent miliary tuberculosis of pleura, mediastinal glands, and peritoneum.

(a.) Mediastinal gland. Miliary tubercles containing giant-cells and epithelioid areas. No bavilli found.

(b.) Peritoneum. A transparent miliary tubercle crushed out and examined in fresh state. Bacilli few around epithelioid cells.

75. Henry P.-Phthisis.-(a.) Tongue. Tubercular ulceration. Submucous and intermuscular miliary tubercles and epithelioid areas. Bacilli in considerable numbers in the floor of the ulceration and in the more superficial tubercles and large-celled infiltration. In a few spots the bacilli were very numerous.

(b.) Caseous abscess of sacro-iliac joint. Bacilli rather few in caseous matter.

76. Thos. A.-Phthisis.-Tubercular ulceration of tongue. Very abundant miliary tubercles and large-celled infiltration in submucous and intermuscular tissue. Caseation beginning in some of above lesions. Fibroid induration in submucosa. Bacilli in enormous numbers in both forms of lesion, both in superficial and deeper parts.

77. John P.-Phthisis.-Tongue. Small tubercular ulcer. Miliary tubercles with giant-cells, epithelioid areas and caseating patches in subepithelial layer, and between muscular bundles. Bacilli very numerous in all the lesions.

78. A case of phthisis.-Transparent miliary tubercle of peritoneum examined fresh. Bacilli few, among epithelioid cells.

79. A case of phthisis.- Miliary tubercle of peritoneum. Examined in fresh state. Contained a few bacilli.

80. Andrew M.-Phthisis.-Thickened pericardium containing scanty miliary tubercles. Some tubercles fibro-caseous, others of reticulated type. One well-marked bacillus found in a tubercle of latter class. No bacilli elsewhere in numerous sections.

81. John C.-Phthisis.-Kidney containing small, irregular, caseating patches in cortex, and small-celled foci. Bacilli few and only in caseous spots.

82. Charles D.-Phthisis.-Caseous masses in kidneys. Smaller masses shreddy, larger ones putty-like. Bacilli very numerous in shreddy parts ; very scanty in older putty-like material.

83. Phthisis.-Tubercular meningitis. Miliary tubercles examined fresh. Bacilli in fair numbers amid the epithelioid cells of perivascular tubercles. 
84. Phthisis. - Tubercular meningitis. Perivascular miliary tubercles, in which caseation was beginning, contained considerable numbers of bacilli among epithelioid cells.

85. Geo. A.-Phthisis. - Tubercular meningitis. Sections of hardened "pia mater" showed well-marked perivascular miliary tubercles, with commencing caseation in most cases. Bacilli in fair numbers both in recent and old tubercles.

86. Charles H.-Abscess of liver.-Vesicula seminalis on one side caseous. Bacilli in moderate numbers in soft caseous contents.

87. John F.-Phthisis.-Bladder. A group of small circular superficial ulcers. Cellular infiltration of mucous coat. No tubercles. Some few bacilli stained blue in base of ulcers. In one section only a minute caseous nodule was seen embedded in the edge of an ulcer. This nodule contained two or three well-marked red bacilli.

88. Jane M.-Phthisis. - Fallopian tube distended with firm caseous matter. Bacilli extremely scanty in caseous contents.

89. Mary Josephine B.-Phthisis.-Uterus with caseous degeneration of its mucous membrane and irregular ulceration. A few bacilli found in caseous lining.

90. Ellen S.-Phthisis.-Scrofulous disease of tarsus and of kidney. (a.) Puriform matter from diseased tarsus contained very numerous bacilli. N.B.-The joint had not been opened, and there was no communication with the atmosphere.

(b.) Caseous masses in kidney contained numerous bacilli.

The results of the examination of the tuberculous cases may be thus stated :

Lung . . 31 cases of nodular lesion. Bacilli found in 24

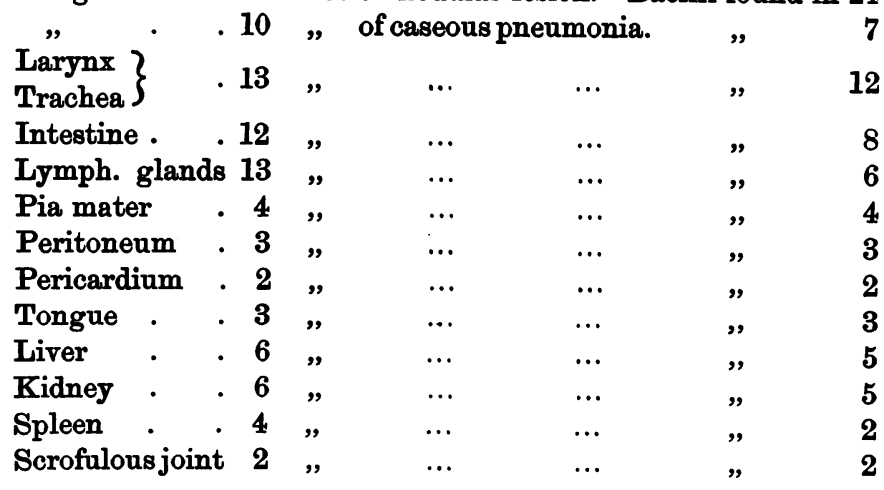

Bacilli were also found in single cases in the vesicula 
seminalis, Fallopian tube, uterine cavity, bladder, and suprarenal body.

With reference to the intestine it must be remembered that in three out of the four cases in which no bacilli were found, there were no "tuberculous" lesions in the base of the ulcers.

In the account of the various cases no detailed record has been given of the examination of the contents of pulmonary cavities. I have never yet failed to find bacilli in the cavity secretions of "tuberculous" cases in a large number of observations. They were most plentiful in vomicæ containing thick caseous secretion, and where the cavity appeared to be of recent formation or was undergoing rapid extension.

Where the secretions were of a thin liquid nature bacilli were less numerous. It would seem that these organisms are practically confined to the superficial, caseous, or suppurating lining of the large cavities. This layer is never without bacilli, and indeed mostly teems with them. If, however, this layer be detached, as may easily occur in making sections, no bacilli may be found; in other words, the bacilli do not penetrate far into the cavity wall. This is what might have been expected, as the fibroid growth in these parts must oppose a barrier to the spread of the bacilli.

In microscopical cavities, on the other hand, where we are able to observe the earliest stages in the process of excavation, bacilli are often found both at the margin of the cavity and extending in large tracts into the surrounding caseous tissues. In such cases no demarcating fibroid zone or capsule has developed round these minute cavities.

Four cases of extensive excavation, probably of bronchiectatic origin, in which one lung was alone affected, and no tuberculous lesions were present, supplied the strongest proof of the diagnostic value of the bacilli in determining whether lung disease is tuberculous or not. In one of these cases repeated examination of the expec- 
toration and of the cavity contents evacuated by puncture of the chest during the patient's life strongly pointed to a disease of a non-tuberculous character.

This conclusion was fully justified at the autopsy by the general appearance of the lung and by the results of a microscopical examination of the contents of the pulmonary cavities. In each case tubercle bacilli were absent, though abundant micrococci were found.

In the other cases similar disease of the lung was found post mortem, $i$. e. cavities with no tuberculous lesion. The cavity contents contained micrococci, but no tubercle bacilli. Here one would think were conditions as favorable as any likely to arise in the human body for the cultivation of micro-organisms. Both patients during their life were placed in wards occupied by phthisical subjects, so that every opportunity was afforded to the tubercle bacilli to take root in the stagnant cavity secretions of these two men. Apparently the soil was not suited for the nurture and development of these organisms, and this observation suggests that very special conditions are required for the entrance and growth of the tubercle bacillus.

Returning now to the strictly tuberculous cases, we find that the bacilli are present in most cases of nodular lesion, but in the case of phthisis their number is as a rule extremely small.

The explanation of this fact may be in part derived from the almost constant association of fibroid growth even with the earliest nodules. It seems possible that although the presence of bacilli is connected with the development of each nodule in the first instance, yet the subsequent fibrosis and caseation may lead to arrest of development or perhaps to destruction of the micro-organisms. What determines the predominance of fibrosis in one case and softening in another it is hard to say. It is true, no doubt, as a rule that in children and young persons softening predominates over fibrosis, the latter process attaining its highest development in persons of more advanced age. 
Or to put it in another way, tissues that are undergoing active growth afford a more luxuriant soil for the development of the bacilli than tissues which are mature or degenerate. Exceptions, however, are not wanting to such general statements, and it is only too plain that the idiosyncracies of tissues in different people are a complete mystery to us.

Whether the final softening of the nodule is the result of an awakened activity of the dormant bacilli or their spores, or whether it is due to a subsequent invasion of these organisms from the air-passages, is a difficult question. It is important to remember the fact, so strongly insisted upon by Koch, that the spores are extremely resistant bodies. Koch found that in certain cases caseous matter apparently containing no bacilli was still infective, and when inoculated set up tuberculosis with a copious development of bacilli. He supposes that in such cases the caseous matter contained the spores, $i . e$. potential bacilli, which only required a suitable nidus for their evolution into mature bacilli. These facts may supply the explanation of the absence of the bacilli in so many of the nodules. It is, however, difficult to account for the rapid disappearance of these organisms from the nodules. I have over and over again examined the earliest miliary granulations I could find in cases of phthisis and always with the same result. Bacilli were always few, and often absent. In the larger nodules, however, where caseation was advanced, bacilli were collected in large groups in many instances.

On the other hand, in the seven cases of acute miliary tuberculosis examined, tubercle bacilli were found in every instance. This is a striking contrast, but I believe it may be explained by the acute nature of the process in this affection as compared with the chronicity of phthisis. It is an interesting fact that out of these seven cases of acute miliary tuberculosis bacilli were only found in extremely large numbers in four, all of which were children. The other three cases were adults. 
With reference to the localisation of the bacilli in the structures comprising the nodule, I have found them in most cases only in what seemed to be caseous alveoli or in alveoli filled with large cells, the so-called epithelioid cells.

In the latter case, these large cells stain only slightly and their outlines are very indistinct, an evidence of the advent of caseation. The bacilli were found in the peripheral fibro-cellular layer in very few instances, and only then in comparatively small numbers. In several such instances they were contained in giant-cells.

In a few cases I met with a distinct tuberculosis associated with the presence of bacilli in the walls of small pulmonary veins, and in one instance an arteriole was similarly affected. Such facts strongly support the views of Weigert as to the path by which the tubercular virus commonly enters the circulation.

I have not succeeded in finding the bacilli in the perivascular and peribronchial small-celled growths. They were present often in large numbers in minute microscopical cavities in the nodules, and to a less extent in the infiltrated lining membrane of the corresponding bronchioles.

There can be little doubt that the bacilli are disseminated in part by the lymphatics of the lung. But the prevailing nodular character of the more recent pulmonary lesions suggests that infection of distant parts is the result of inhalation.

In the first case, infection probably takes place from atmospheric sources, as Koch believes, whereas in the later stages this must be largely supplemented by aspiration into the lung of the contents of the cavities.

It is equally difficult to explain the capricious localisation of bacilli in the caseous pneumonic tracts. I can only suggest a similar explanation to that offered in the case of the nodular form. In some of the most severe cases of phthisis, caseous pneumonia is the predominant lesion. It seems doubtful whether any cases of phthisis 
commence as a massive pneumonic consolidation. At any rate the pre-existence of a nodular stage can hardly be excluded. If we consider that the primary local manifestation of the disease is nodular it requires no great stretch of imagination to regard widespread consolidation, like caseous pneumonia, as secondary to the presence of discrete nodules. There is ample evidence that this is frequently the sequence of events in the later stages of the disease. Or it may be, as Mr. Watson Cheyne suggests, that in caseous pneumonia the virus is inhaled into the individual alveoli. If this were the case we should expect to find bacilli distributed widely through the consolidation. This, however, has not been my experience. It may be that caseous pneumonia is set up in another way. In certain cases where cavities or rapid softening are present we are reminded that septic processes are going on, not only by the character of the attendant pyrexia, but often also by the odour of the patient's breath. The -products of this process are probably gaseous to some extent, and can hardly fail to be inhaled into the alveoli. This may play some part in the production of those large caseous patches so often found in the sternal region in cases of advanced destruction of lung.

I have been unable to find any bacilli in those parts of the lung that have undergone a dense fibroid change. Neither have I succeeded in detecting their presence in the pigmented giant-cells often enclosed in the fibroid tissue, except in the outer fibro-cellular zone of the nodular growths. Here I have found them in several cases. It may now be asked whether there is any evidence that the evolution of each individual nodular lesion of phthisis is invariably associated with the presence of the tubercle bacilli. The answer, I believe, must at present be, that although this is highly probable direct proof is wanting.

It is probable that the presence or absence of these organisms is closely connected with the stage of development of the nodules. The presence of comparatively 
large numbers of bacilli in caseous matter (whether nodular or otherwise) as soon as actual softening occurs, lends countenance to the idea that this is largely connected with, if not actually due to, communication with the atmosphere. The enormous numbers found in the cavities as compared with the small number in the solid lesions is a sufficient proof that the presence of air is favorable to their growth. It is still unknown on what the softening process primarily depends. It is possible that bacilli or their spores may remain shut up for months or years in a caseous mass, until some other agency starts the chemical processes necessary for the solution of the caseous matter.

Softening has been likened to the ripening of cheese, but what determines this ripening of caseous matter remains to be discovered.

Passing now to the larynx, it is seen that in all the cases of tuberculosis examined bacilli were detected. Nevertheless, in only a very few cases were they abundant and widely distributed. In one case of tracheal ulceration in which no tuberculous structure existed, no bacilli were found.

It would seem premature to revert at once unreservedly. to the views of Louis, and ascribe all tuberculous lesions of the larynx to contamination from the pulmonary sputum. For, as has been pointed out by Heinze and others, it is not uncommon to meet with advanced laryngeal disease in which there is little or no expectoration and only very slight signs of pulmonary mischief. Most clinical observers have met with cases of very early pulmonary phthisis associated with great swelling (tuberculous) of parts of the larynx without any obvious ulceration.

A typical instance of this is presented by the so-called turban-shaped thickening of the epiglottis found sometimes at an early stage in the development of laryngeal phthisis. This swelling of the mucous membrane may be unassociated with any visible ulceration.

How then did the virus contained in the sputum find its way into the deeper layers of the mucous membrane? 
It may be argued that it is impossible to exclude the existence of some minute abrasion or of some distinct ulceration in remote parts like the ventricles of Morgagni.

It is a fact, however, that ulceration is uncommon in this position, perhaps owing to the fact that the epithelium of the ventricles is ciliated and prevents the secretions from accumulating. Moreover, it may be fairly expected that where the tubercular virus makes its entry, it will give rise to ulceration or some local manifestation. In addition to these objections to the acceptance of Louis' doctrine, it has been shown by Heinze that in some cases tuberculosis of the larynx commences distinctly in its deeper layers. I have seen such instances myself. It seems improbable then that such cases as have been just mentioned are the direct result of absorption of some virus from the surface; but whether they are to be explained by infection through vascular channels is uncertain.

That the laryngeal affections of the later stages of phthisis are largely due to absorption from the virulent sputa is highly probable. Clinical and pathological experience both show that at these stages the laryngeal tuberculosis often starts from the surface. It seems little short of marvellous if Louis' doctrine be exclu. sively adopted, how so many cases of phthisis escape without any laryngeal disease, unless we consider that the thickness of the epithelium of the larynx is a sufficient explanation. The same difficulty meets us in the case of the trachea where the epithelial layer is much thinner.

With reference to the influence on the bacilli of the fibroid element of tuberculosis, it is well known that this plays a comparatively small part in tuberculous laryngitis as a rule. The tendency of the tubercles and other lesions is to undergo an ulcerative rather than an indurative change. Still, in many cases, the tubercles present a wellmarked fibro-cellular reticulated zone at their periphery, indicating a tendency to fibrosis. Sometimes distinct fibroid tracts are distributed widely through the submucosa. 
In the thirteen cases of intestinal ulceration examined, bacilli were found in eight cases only.

In four cases bacilli were plentiful.

Three of the cases which gave a negative result as regards bacilli presented no typical tuberculous changes, and although the ulceration was slight the mucous coat was greatly atrophied.

In the fourth case, the ulceration was probably due to old dysentery and was in no sense tuberculous. No bacilli were found.

In all the other cases the disease was distinctly tuberculous.

Of the thirteen cases in which lymphatic glands were examined the bacilli were plentiful in three only ; in three other cases they were very scanty. In seven cases none could be found.

It seems remarkable at first sight that the mediastinal glands contained so few bacilli. But it is worthy of note that all the glands examined were those of adults, most of whom were dwellers in towns. It is possible that the pigmentation and induration which is so common in the mediastinal glands of such persons renders them less suited for the growth of the bacilli.

The abundant pigment in the glands may possibly obscure the presence of the bacilli to some extent when they are very scanty. The number of bacilli found in these and other glands depends mainly, however, I believe, on the stage of the disease. When the tuberculosis is quite recent they are abundant; in the later stages it may be impossible to discover any at all. The observations referring to other organs than the lung, air-passages, intestine and lymphatic glands are too scattered and few to be of much value.

But the detection of the bacilli in such widely different places as the peritoneum, pia mater, kidney, liver, spleen, tongue, caseous joint and vesicula seminalis, Fallopian tube, uterus, and suprarenal capsule is worthy of note.

It is impossible to doubt that the presence of certain 
bacilli is indissolubly bound up with the process of "tuberculosis," although their distribution appears at present to be somewhat capricious.

In pulmonary cavities and in softening caseous matter, wherever it may occur, so long as it be associated with "tuberculous" or scrofulous affections, there we may be sure of finding Koch's bacilli.

It is probable also that in all lesions termed "tuberculous," the same bacilli can be found at certain stages of their development by careful search, if a sufficient number of sections be examined.

But although the extremely small and even insignificant number of these organisms found in many cases of advanced and wide-spread "tuberculous" disease may be to some extent explained, it will appear to many, perhaps, improbable that the presence of a few bacilli can be the sole cause of such extensive structural changes.

I would, however, express the belief that as we know more of the various conditions incidental to the life-history of organisms like the tubercle bacillus, we shall be able to account for much that at present looks like irregularity and caprice in the behaviour of these parasites.

On the other hand it is much to be hoped that Koch's brilliant and valuable discovery may not entirely divert attention from the important influence of constitutional disposition or diathesis in the production of the various affections now grouped together as tuberculous.

(For report of the discussion on this paper, see 'Proceedings of the Royal Medical and Chirurgical Society,' New Series, vol. i, p. 303.) 


\section{DESCRIPTION OF PLATES I AND II.}

"Tubercle Bacilli" in the Lesions of Phthisis. (PERCY KIDD, M.A., M.D. Oxon.)

Fra. 1.-Acute miliary tuberculosis. Case 35.-Lung: two alveoli which have become fused together. Alveoli filled with large epithelioid cells. Tubercle bacilli in large numbers between the cells, and in a few instances within the cells $(a, a)$.

$\times 400$.

FIa. 2.-Acute miliary tuberculosis. Same case.-Lung : arteriole from one of the nodules. Walls of vessel thickened and infiltrated, with epithelioid cells scattered through a finely granular substance (commencing caseation). Calibre of vessel encroached upon by the growth. Vessel still patent, and occupied by blood-corpuscles.

a. Thickened wall of vessel.

b. Remains of muscular coat.

c. Cavity of vessel filled with red corpuscles, and containing a few leucocytes stained blue. $\times 200$.

FIG. 3.-Phthisis. Case 16.-Lung : section from wall of minute cavity. Inner margin of cavity teeming with bacilli. No bacilli elsewhere.
a. Cavity.
b. Bacillary margin.
c. Surrounding caseous tissue.

$\times 75$.

FIG. 4.-Phthisis, with intestinal ulceration. Case 70.-Mesenteric gland. Follicle from gland containing numerous bacilli, and surrounded by a broad caseous zone teeming with bacilli. The follicle has separated from the caseous zone in the process of preparation.

a. Follicle.

b. Caseous zone.

c. Space due to shrinking of follicle from surrounding zone. 
Plates I i II

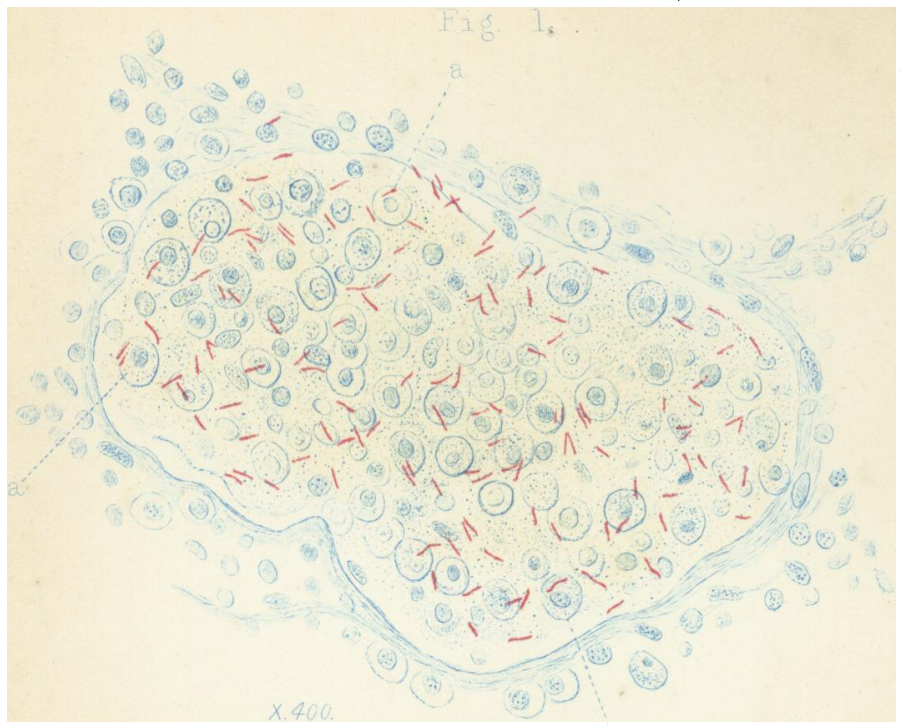

Tugar Thurar: .. 
Med..Chir. Trans. Vol . LXVIII.

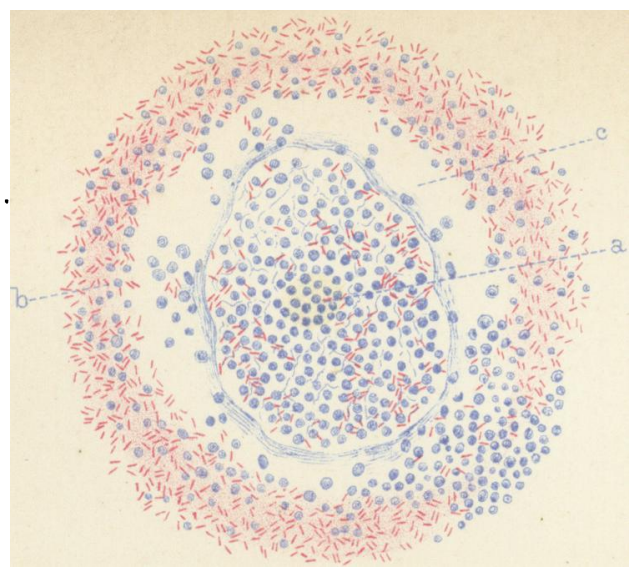

$$
\text { T. } 2 .
$$

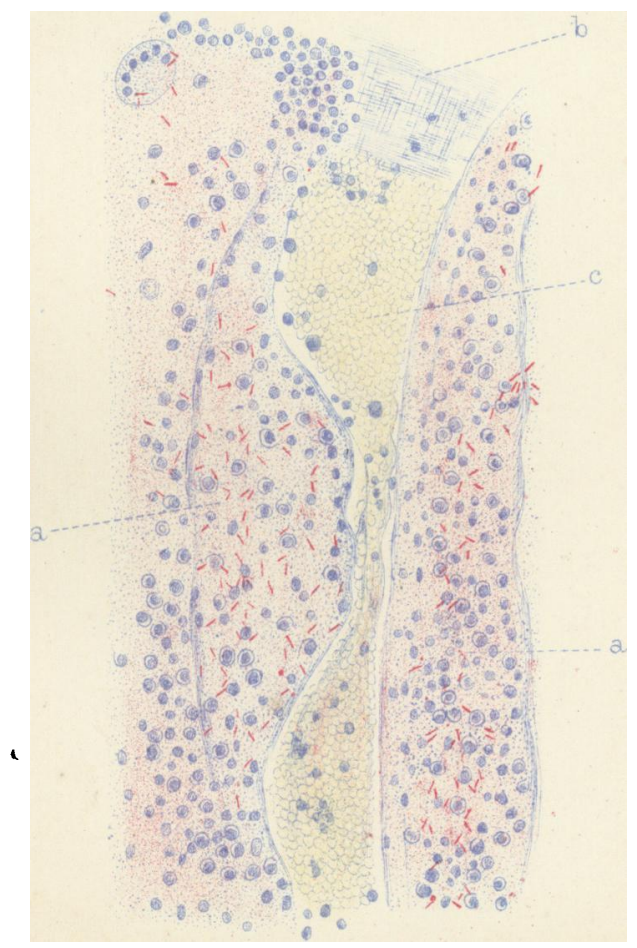

$$
\text { Fig. } 4 \text {. }
$$

